\title{
Fabrication, Mechanical Characterization and Interfacial Properties of Okra Fiber Reinforced Polypropylene Composites
}

\author{
A. N. M. Masudur Rahman', Shah Alimuzzaman', Ruhul A. Khan², Md. Ershad Khan ${ }^{3}$ and \\ Sheikh Nazmul Hoque ${ }^{3}$
}

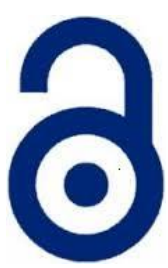

Received: 04 February 2017

Accepted: 04 March 2018

Published: 30 March 2018

Publisher: Deer Hill Publications

(c) 2018 The Author(s)

Creative Commons: CC BY 4.0

\begin{abstract}
In this study, an attempt has been taken to manufacture okra fiber (OF) composites with varying the fiber content ranging from $25-65 \%$ on total weight of the composites and polypropylene (PP) was preferred as matrix material. To fabricate the composites untreated and mercerized fibers were selected. A systematic study was done to observe the mechanical behaviors of the composites such as tensile, impact and bending properties. It was found that treated (mercerized) fiber composites exhibited improved mechanical properties than that of untreated fiber composites. Maximum tensile strength (TS) and bending strength (BS) was examined $38.5 \mathrm{MPa}$ and $72.5 \mathrm{MPa}$ respectively, whereas the highest tensile modulus (TM) and bending modulus (BM) was observed $675 \mathrm{MPa}$ and $5.4 \mathrm{GPa}$ respectively. The optimum impact strength (IS) and hardness value was found to be $22.87 \mathrm{KJ} / \mathrm{m}^{2}$ and 97 (Shore-A) for mercerized fiber composites containing $45 \%$ fiber. The composite samples were exposed to different intensities of $y$ radiation $(2.5 \mathrm{kGy}-10.0 \mathrm{kGy})$ and found significant improvement in the mechanical properties up to $5.0 \mathrm{kGy}$ dose. Water absorption, degradation properties due to heat and soil medium of the composites were also performed. The interfacial property was examined by Microscopic Projector and Scanning Electron Microscope (SEM) and found that the interfacial bonding between matrix material and fiber was enhanced due to the treatment of fibers which authenticate the found mechanical characteristics of the composites.
\end{abstract}

Keywords: Okra Fiber, y Radiation, Polypropylene, Composites, Compression Molding, Mechanical Properties, Composite Degradation.

\section{INTRODUCTION}

Recently, fiber reinforced composites have appealed huge consideration in the arena of engineering applications because of their excellent and unique combination of physical and mechanical properties. The bast fibers such as jute, flax, hemp, ramie, sisal, kenaf are presently using as reinforcement in polymer composite and many efforts have been made by researchers to establish natural biodegradable fiber as substitute of synthetic fiber to use effectively in the composite material. Several studies reported that incorporation of lingo-cellulosic fiber improves the physicomechanical properties of polymer matrices in the composite material [1-13]. Scientists prefer thermoplastic composites than thermoset because of low production cost and lower processing cycle. Synthetic fiber reinforced thermoplastic composites are dominating over natural fiber reinforced composites due to their higher strength, stability and corrosion resistance properties. But synthetic fibers are not decomposable and are causing ecological pollution. Due to increasing environmental consciousness, composites made of lingo-cellulosic fibers as reinforcing material are exploring day by day [14-17].

Okra fiber (OF) is obtained from okra plant. The scientific name of the plant is Abelmoschus esculentus which is under the family of Malvaceae, abundantly available in Bangladesh and also in some other tropical countries in the world. Fibers can be extracted from the outward cell layers of the stem [18, 19]. Presently the fiber has no economic value as the plant is subjected to combustion [20]. But the mucilage of okra fiber can be applicable for

A. N. M. M. Rahman ${ }^{1}$, S. Alimuzzaman', R. A. Khan², M. E. Khan ${ }^{3}$ and S. N. Hoque

'Department of Fabric Engineering, Bangladesh University of Textiles, Tejgaon, Dhaka-1208, Bangladesh

${ }^{2}$ Institute of Radiation and Polymer Technology, Bangladesh Atomic Energy Commission, Dhaka-1349, Bangladesh

${ }^{3}$ Department of Textile Engineering, Ahsanullah University of Science and Technology, Tejgaon, Dhaka-1208, Bangladesh

E-mail: masudfabric@yahoo.com

Reference: Rahman, A. N. M. M., Alimuzzaman, S., Khan, R. A., Khan, M. E. and Hoque, S. N. (2018). Fabrication, Mechanical Characterization and Interfacial Properties of Okra Fiber Reinforced Polypropylene Composites. International Journal of Engineering Materials and Manufacture, 3(1), 18-31 
the production of decomposable polymer materials with proper grafting process [21]. The composition of OF is hemicellulose (15-20\%), $\alpha$-cellulose (60-70\%), pectin (3-5\%) and lignin (5-10\%). The fiber showed improved tenacity (40.1-60.5 MPa) and moderate elongation at break (3-6\%) also [22, 23]. The current study of mechanical and morphological properties of okra fiber confirm that it can be a potential candidate as reinforcing material in the composite field which is comparable to those of other common lignocellulose fibers like jute, hemp, flax, pineapple leaf fiber [18].

Natural fibers have several advantages; for example, they have acceptable toughness, cheaper, improved strength, recyclable, biodegradable and cause no skin irritation [24-28]. Although several advantages, cellulosic fibers endure the drawback of nonresistance to high temperature and proneness to moisture absorption [29]. The composites prepared with nonpolar thermoplastic matrix and hydrophilic natural fiber result in reduced mechanical properties due to the poor affinity between the plastic material and fiber [30]. The mechanical properties of the composites can be enhanced by modification of natural reinforcing fibers by various physical and chemical methods such as alkali/mercerization, monomer grafting under UV and $\gamma$ radiation [31].

In this study, polypropylene (PP) was selected as thermoplastic resin because it possesses several outstanding properties like very good surface hardness, higher impact strength, superior abrasion and heat resistance. PP with biodegradable fibers can be a favorable way to produce the combination of synthetic-natural polymer composites $[32,33]$.

The present study was designed to fabricate partially degradable composites using okra fiber as reinforcement and polypropylene as matrix. Untreated and mercerized fibers were used to prepare the composite. So, mechanical properties were compared between two types of composites. The optimum fiber content in composites was evaluated based on mechanical performance showed by the composites. Thermal aging, degradation under soil medium and water absorption capability were also observed for the optimized composites to investigate the suitability of the composites for wide-ranging applications. The morphology was evaluated by analysis of SEM.

\section{METHODOLOGY}

\subsection{Materials}

Okra plant has been collected from Gazipur District (Bangladesh). About three months old and around $2.5 \mathrm{~m}$ high plants were collected. After collection, the middle portion of the stems was separated and then dipped under water for retting. Fiber geometry and mechanical properties of fibers strongly depend on stem age [34]. The stems were degraded sufficiently within 15-20 days to allow the collection of fibers. The degraded stems were washed several times using distilled water and then the fibers were obtained. They were dried in open air and reserved in fresh container afterward [19, 35].

\subsection{Surface Modification}

To remove natural impurities (lignin, pectin and wax), the fibers were mercerized using $5 \% \mathrm{NaOH}$ solutions for 45 minutes at $70-80^{\circ} \mathrm{C}$. Then the treated fibers were dried for one week at room temperature and desiccated at the temperature of $100^{\circ} \mathrm{C}$ for 10 minutes in a hot air oven to remove the presence of any moisture. The color of the fibers was changed from brown to silvery white after mercerization. The change of surface (Figure 2) and diameter of the fibers (Figure 15) was measured by using the microscopic projector.

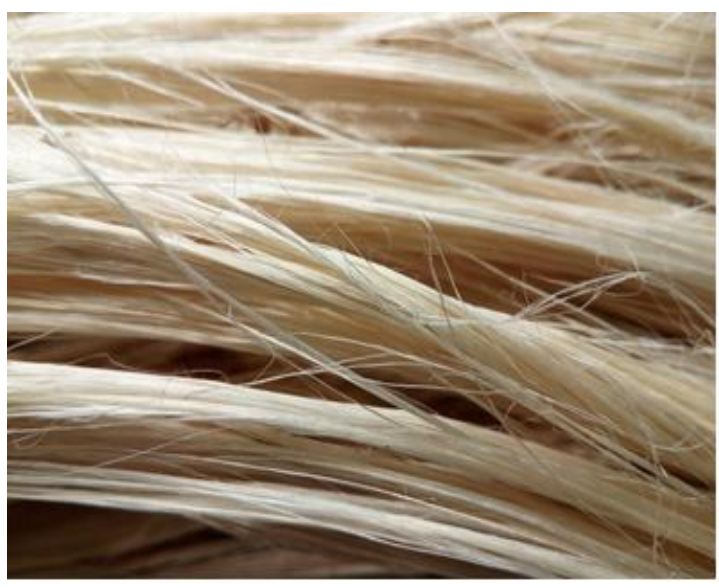

(a)

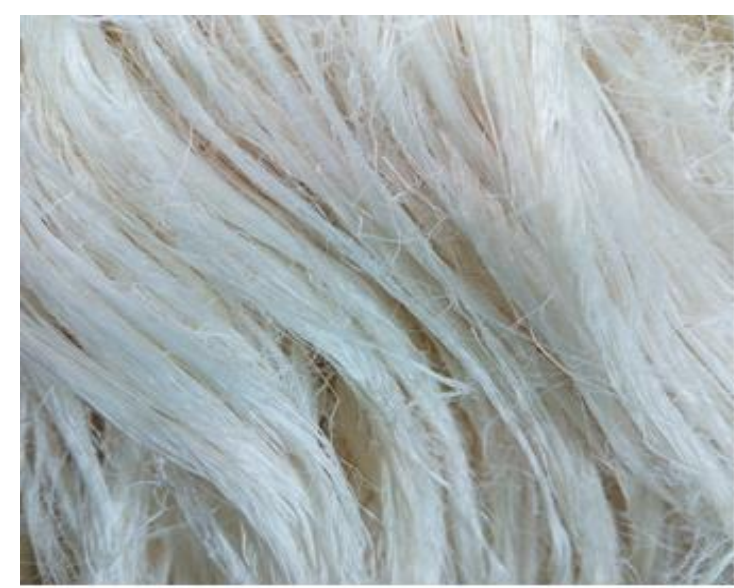

(b)

Figure 1: (a) Untreated and (b) Mercerized okra fiber 


\subsection{Composite Fabrication}

At first polypropylene sheets were prepared from granules. The preweighted granules were heated for $5 \mathrm{~min}$ at $190^{\circ} \mathrm{C}$ temperature by placing them in between two steel plates in a compression molding machine. The model of the machine was 3856, Carver Incorporation, USA. Cooling was done another compression molding machine of same model for 5-7 min at room temperature using 5 Metric Ton pressure. The resultant polypropylene sheets were cut to the desired size $(12 \mathrm{~cm} \times 12 \mathrm{~cm})$ for composite manufacturing. Okra fibers were cut into the length of 20-25 mm. Four layers of fibers were inserted between five sheets of preweighted polypropylene during the fabrication of composite. The fibers were embedded randomly in between polypropylene sheets. By this way, a sandwich is formed which was then employed between two steel plates under a pressure of 5 Metric Ton for 5 min with keeping the temperature of $190^{\circ} \mathrm{C}$ (shown in Figure 3). The thickness of the resultant composites was kept $2 \mathrm{~mm}$. Testing specimens were prepared from the composite sheet by cutting with grinding machine carefully.

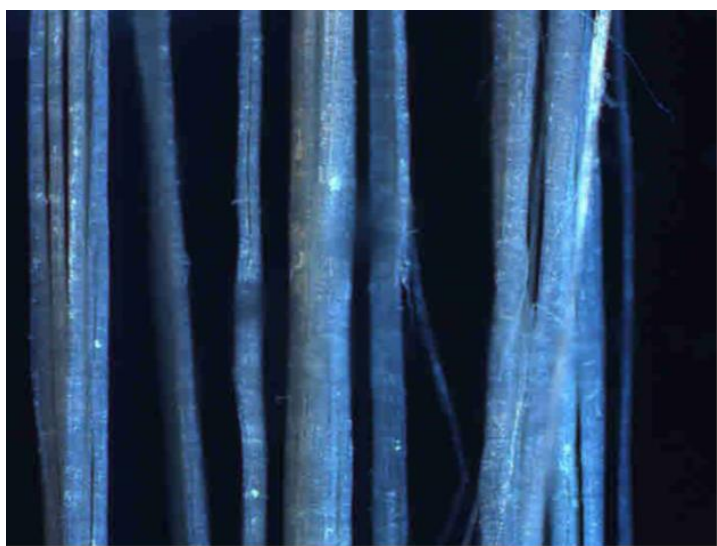

(a)

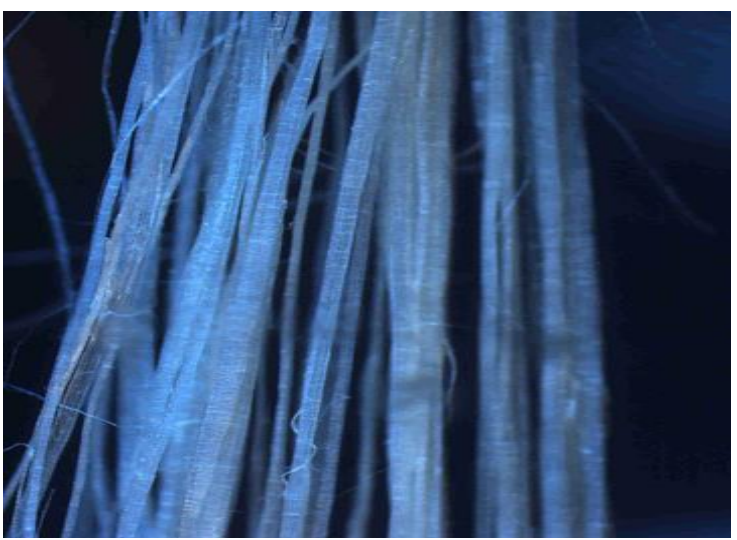

(b)

Figure 2: The Surface image of (a) untreated OF and (b), mercerized OF

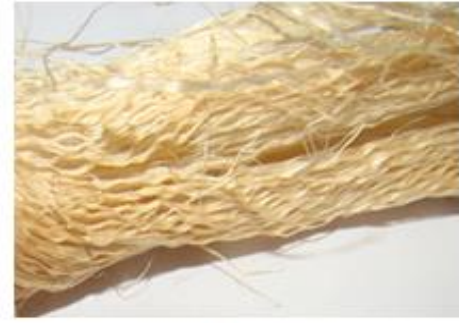

Okra Bast Fiber

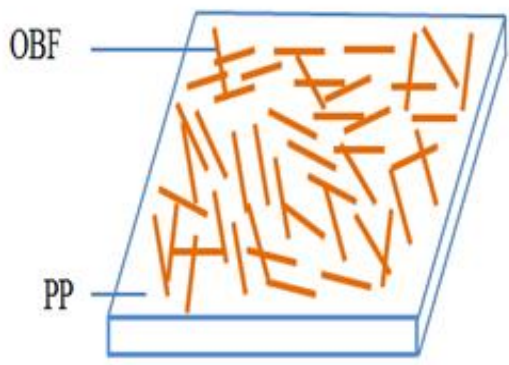

Manufactured Composite

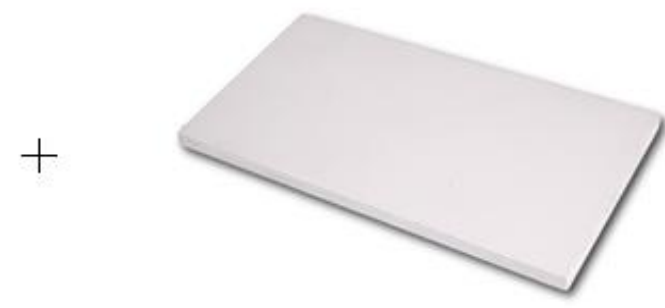

PP Sheet
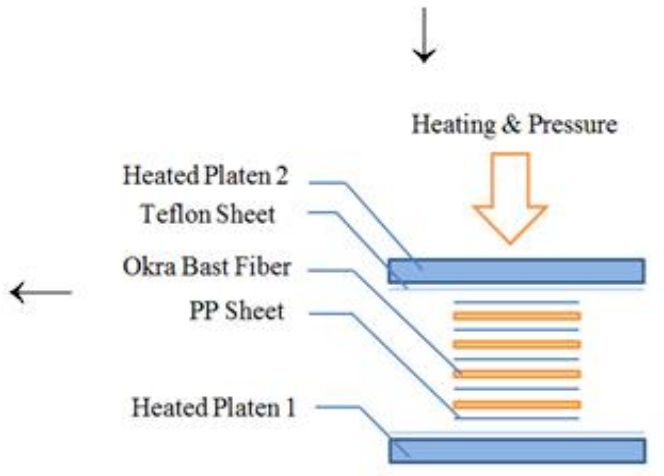

Compression Molding

Figure 3: Fabrication Model of Composite Manufacturing 


\subsection{Testing of Mechanical Properties of the Composites}

Tensile strength, tensile modulus, elongation at break (\%) was investigated by following the DIN 53455 standard method using a Hounsfield S series Universal Testing Machine, model: H 50 KS-0404. The cross-head speed was set $10 \mathrm{~mm} / \mathrm{min}$ during testing and the gauge length was $20 \mathrm{~mm}$. The geometry of the test specimen was maintained $60 \mathrm{~mm} \times 15 \mathrm{~mm} \times 2 \mathrm{~mm}$. Bending strength and bending modulus were examined according to DIN 53452 by means of above-mentioned equipment. The test speed and span distance was $10 \mathrm{~mm} / \mathrm{min}$ and $40 \mathrm{~mm}$ respectively. The charpy impact strength was performed by maintaining the standard of DIN EN ISO 179 in the un-notched, flat mode by means of a pendulum type impact testing machine (Model-3016, Germany). The hardness of the composite samples was tested by an HPE Durometer (model type 60578, Germany) according to DIN 53505 standard. The mechanical properties of unreinforced polypropylene sheet were also tested according to the abovementioned method.

Prior to testing all the testing specimens were conditioned at $25^{\circ} \mathrm{C}$ and $50 \% \mathrm{R} . \mathrm{H}$ for several days. All the mechanical properties of composites were tested under the similar conditions. The average value of five samples was taken as the final value of all tests.

\subsection{Irradiation}

The composite samples were exposed to irradiation for different doses (2.5-10.0 kGy) with a dose rate of 3.3 $\mathrm{kGy} / \mathrm{hr}$ by using the available $y$ source of Cobalt 60 (90.0 kCi) of the BAEC, Savar, Dhaka.

\subsection{Water Absorption}

Water absorption ability of composite samples was carried out in deionized water. The experiment was done at room temperature $\left(25^{\circ} \mathrm{C}\right)$ for $90 \mathrm{hr}$ into a glass beaker containing $100 \mathrm{ml}$ water. The size of the specimens was 20 $\mathrm{mm} \times 10 \mathrm{~mm} \times 2 \mathrm{~mm}$. The samples were dried at $105^{\circ} \mathrm{C}$ in an oven before dipping, then cooling was done in a desiccator and the weight was measured. After different soaking period, the mass of the samples was taken by withdrawing them from the beaker. Water absorption was calculated by the following formula: $W_{g} \%=\left[\left(W_{a}-\right.\right.$ $\left.\left.W_{0}\right) / W_{0}\right] \times 100$, where $W_{g}$ is the water absorption (\%), $W_{0}$ denoted the mass of the specimens before dipping in and $W_{a}$ indicated the mass of the test samples after water treatment.

\subsection{Thermal Degradation Test}

For determination of thermal aging, a thermo stated oven was selected and the test was continued up to the time period of 30 days. Model of the instrument was Denver, AA-160. After a certain time (5 days), samples were taken out from the oven and reserved at $25^{\circ} \mathrm{C}$ for $24 \mathrm{~h}$ for testing the tensile properties.

\subsection{Assessment of Soil Degradation}

Untreated and mercerized composite test samples were buried in soil at $15 \mathrm{~cm}$ depth for the assessment of degradation behavior of the composites in soil medium. The soil should contain at least $25 \%$ moisture and the assessment was continued up to 24 weeks. After a certain time, samples were taken out from soil followed by washing with purified water and then dried for $6 \mathrm{hr}$ keeping the temperature of $105^{\circ} \mathrm{C}$. The samples were preserved for $24 \mathrm{hr}$ at room temperature for conditioning to observe the tensile behaviors.

\subsection{Examination of Interfacial Property}

SEM micrographs were taken from a scanning electron microscope (model JS 6490, Japan). Tensile fracture samples were selected for analysis of SEM. The dimension of the specimens was $2 \mathrm{~mm} \times 2 \mathrm{~mm}$ and the experiment was done at room temperature using $20 \mathrm{KV}$ acceleration voltage.

\section{RESULTS AND DISCUSSION}

\subsection{Influence of Fiber Loading}

To understand the mechanical attributes of a polymer composite several parameters need to be analyzed. These parameters greatly influence the performance of a composite and those are alignment of fiber, fiber-matrix ratio, fiber-matrix interfacial bonding [36, 37]. The fiber loading was varied in the composites from 25 to $65 \%$ on the weight basis of the composites. Moreover, compatibility between matrix and fiber play a vital role on tensile behavior of the composites [38]

Influence of fiber filling (wt. \%) on the mechanical properties of resultant composites was examined and the results are plotted in Figure 4-8. It was observed that tensile, impact and bending properties were improved with the filling of the fiber up to $45 \%$ in the composite and after that considerable amount of reduction in mechanical properties were found with the rising of fiber loading in the composite (Figure 4, 6 and 8). At the level of $45 \%$ fiber loading, tensile, bending and impact strength of the virgin samples were examined to be $33.2 \mathrm{MPa}, 57.2 \mathrm{MPa}$ and $20.84 \mathrm{~kJ} / \mathrm{m}^{2}$ respectively. For treated fiber composites that values were observed to be $38.5 \mathrm{MPa}, 72.5 \mathrm{MPa}$ and $22.87 \mathrm{KJ} / \mathrm{m}^{2}$ respectively. It was also testified that tensile and bending modulus of the composites improved with the increment of fiber ratio up to $45 \%$ in the composites and above $45 \%$ fiber ratio, tensile and bending modulus of the composite declined considerably with the growth of fiber volume (Figure 5 and 7) for both type of 
composites. The reason behind such result may be ascribed to the fact that with the increase of fiber volume in the composite the fiber-matrix interface was lessened due to reduced wetting tension [39].

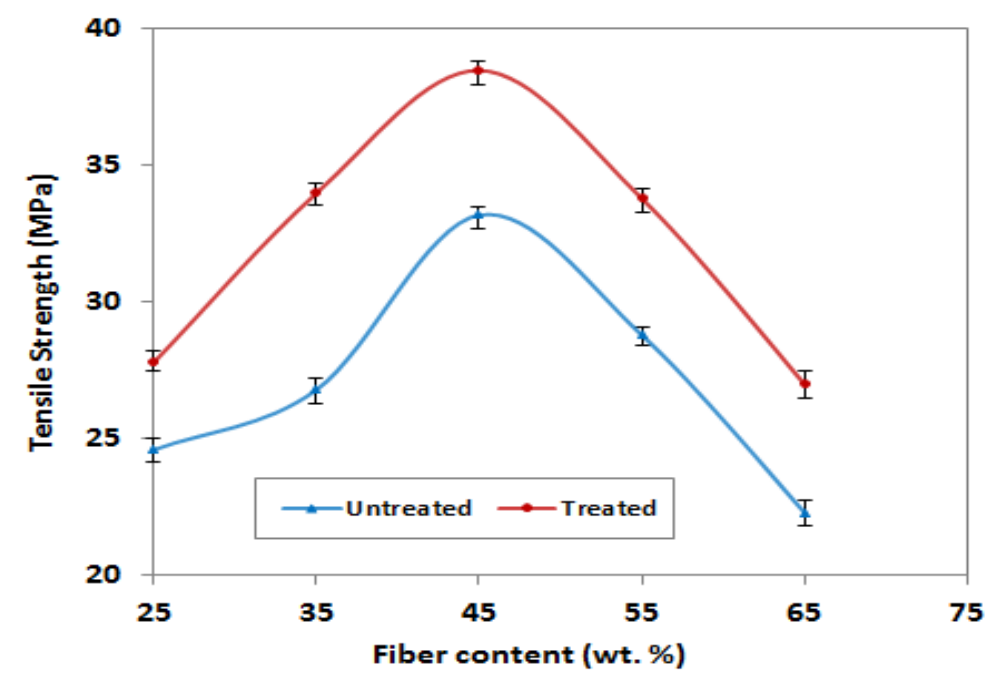

Figure 4: Comparative tensile strength of the resultant composites with respect to fiber loading.

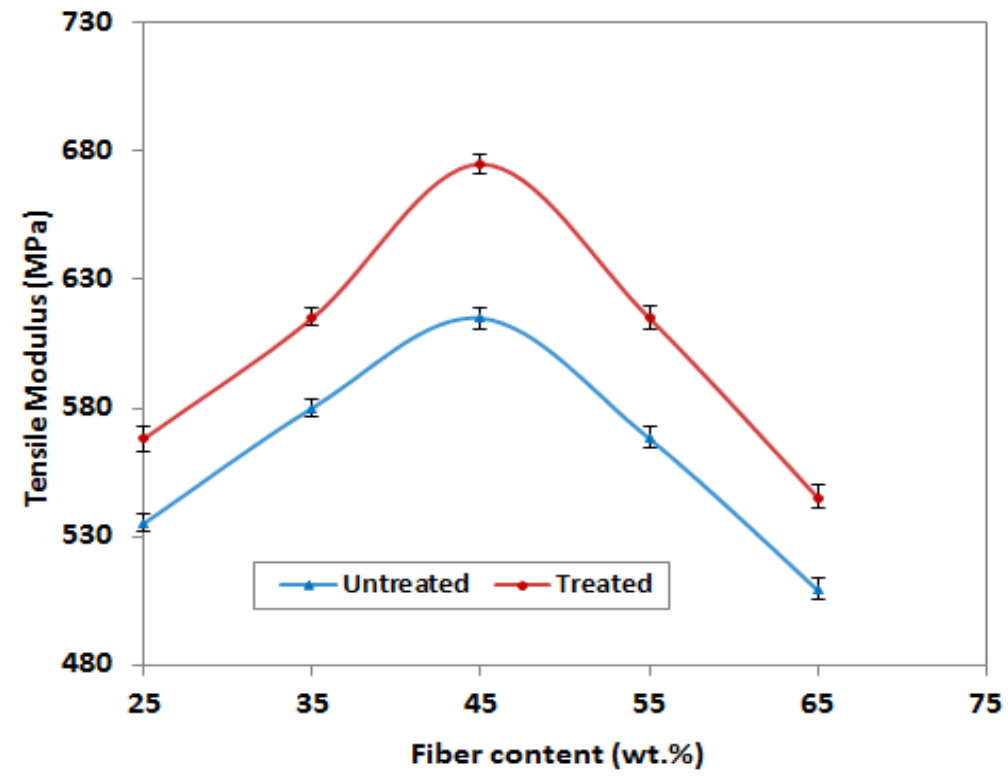

Figure 5: Comparative tensile modulus of the resultant composites with respect to fiber loading. 


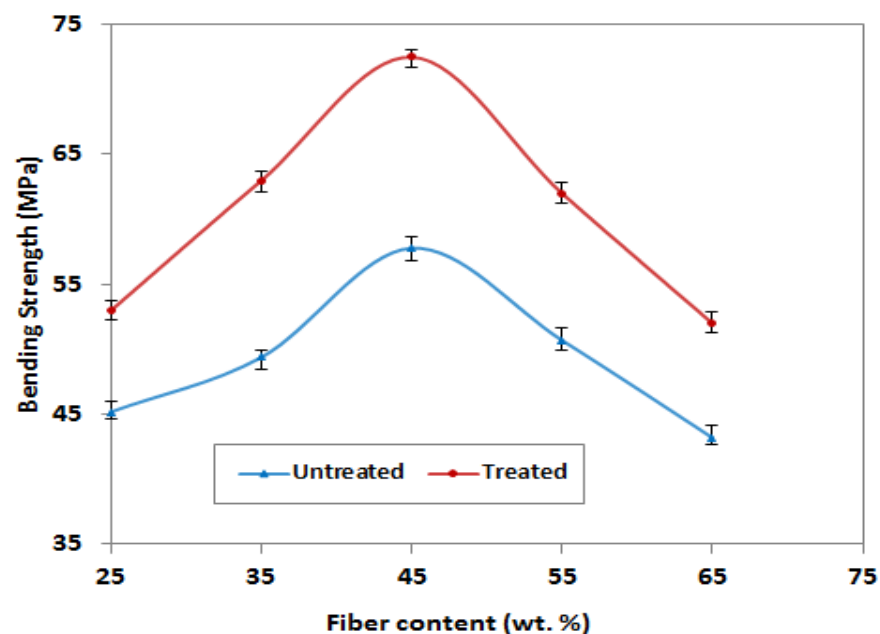

Figure 6: Comparative bending strength of the resultant composites with respect to fiber loading.

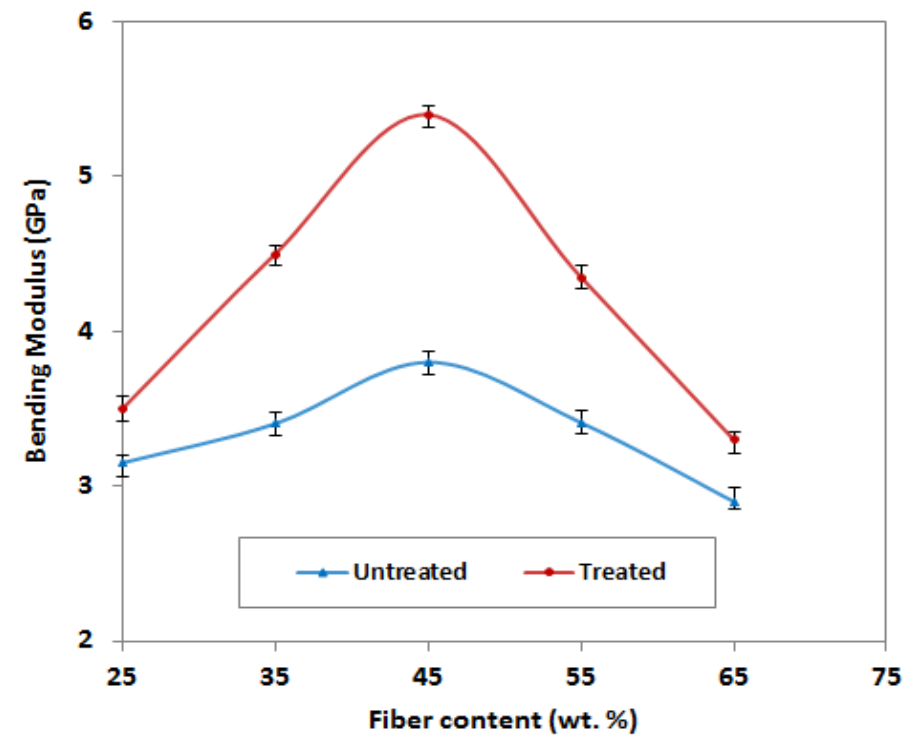

Figure 7: Comparison between bending modulus of the resultant composites with respect to fiber loading.

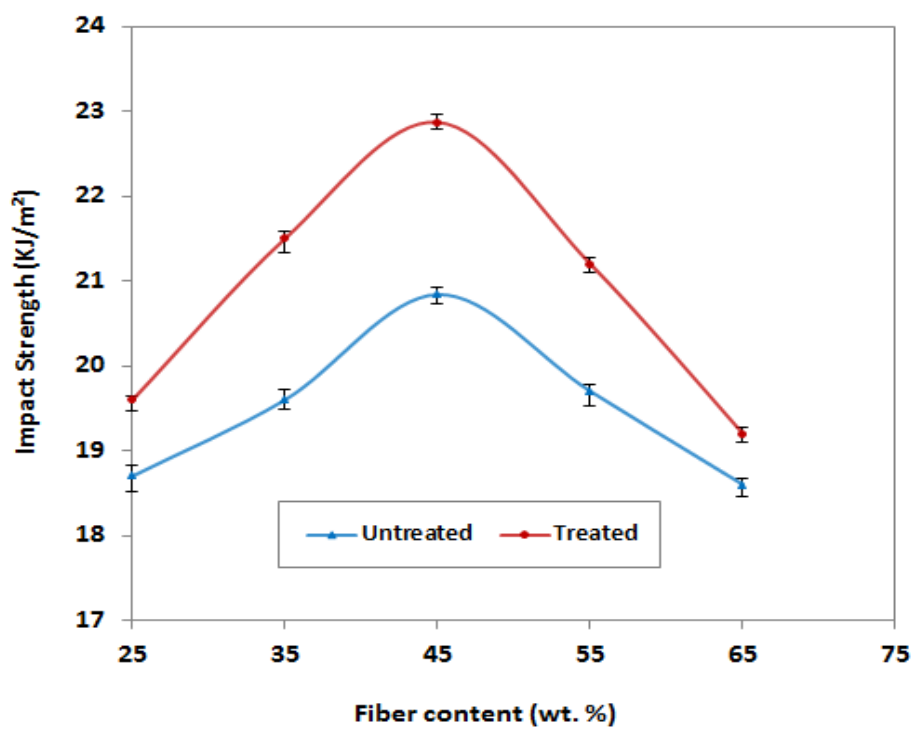

Figure 8: Comparative impact strength (charpy) of the resultant composites with respect to fiber loading. 
The tensile and bending modulus of untreated fiber composites having $45 \%$ fiber content show the value of 615 MPa and 3.8 GPa respectively. Similarly, TM and BM value were found $675 \mathrm{MPa}$ and $5.4 \mathrm{GPa}$ respectively for treated fiber composites (45\% fiber). From this analysis, it can be concluded that at the level of $45 \%$ fiber loading, the composites achieved the best mechanical characteristics. So, at the configuration of $45 \%$ fiber loading was found to be the optimal configuration. The composite performs poor mechanical properties due to reduced population of fibers with minor load transmission capability to each other at the lower level of fiber filling. At this level, the stress gathered at some points and extremely localized strains arise in the binder material. At $45 \%$ fiber content, the fibers participate in stress transfer very actively because the optimum alignment was found at this stage. A higher level of fiber loading increased the fiber agglomeration, as a result, cluster can be created and stress transferring should be blocked. So, failure occurs in the composite followed by initiation of cracks. The serviceability of the bio-composite might be failed by introducing the failure of the plastic material at first and breakage of reinforcing fiber afterward [40, 41].

\subsection{Investigation of Mechanical Properties of the Composites}

The tensile properties of a material give the information how it behaves during the application of axial loading. The mechanical properties of unreinforced PP, untreated and treated OF/PP ( $45 \%$ fiber by wt.) composites were investigated. The obtained values are given in Tables 1-2. Analyzed data revealed the value of TS, TM, EB (\%), BS, $\mathrm{BM}$, IS and hardness was 20.5 MPa, 492 MPa, 375\%, 35.5 MPa, 1.9 GPa, $4.55 \mathrm{KJ} / \mathrm{m}^{2}$ and 92 Shore-A respectively for PP sheet. Investigation showed that both raw and treated fiber composites achieved a substantial enhancement of their mechanical attributes which indicated the successfulness manufacture of the reinforcing fibers with PP matrix. The tensile strength and tensile modulus of virgin fiber composite improved to 62 and $25 \%$ respectively than PP matrix. From the analytical data, it was also found that bending strength, bending modulus and impact strength also improved to 61,105 and $358 \%$ respectively for virgin fiber composites over the PP matrix. The treated fiber composite showed 88, 37, 104, 184 and 402\% increase of TS, TM, BS, BM and IS respectively over the PP matrix. On the other hand, EB\% was reduced significantly due to lower elongation of the natural fibers. The value of hardness was found to be 95 and 97 (Shore-A) for untreated and treated fiber composite respectively. It can be concluded that untreated fiber composites showed comparatively lower improvement in mechanical properties related to mercerized fiber composites.

It was reported that the treated fiber composite gained 16 and $10 \%$ increment of TS and TM than the untreated fiber composite. The BS, BM and IS of the treated fiber composite is improved 27, 38 and $10 \%$ higher than the raw fiber composite. During alkali treatment, the interface between fiber and matrix was improved for subtraction of dirty substances from the fiber and produces high-quality fibers. Mercerization also decreases fiber diameter also improves the surface roughness. The surface geography and enhancement in aspect ratio compromises better interfacial bond and developed the ultimate mechanical properties. The increment of surface roughness which creates better mechanical interconnecting between fiber and matrix was found due to mercerization.

Table 1: Comparative tensile and bending properties of unreinforced PP sheet and the optimized composites (45\% fiber content) found in this study

\begin{tabular}{llllll}
\hline Materials & \multicolumn{2}{l}{ Tensile Properties } & \multicolumn{2}{l}{ Bending Properties } \\
& TS $(\mathrm{MPa})$ & TM $(\mathrm{MPa})$ & $\mathrm{EB}(\%)$ & $\mathrm{BS}(\mathrm{MPa})$ & $\mathrm{BM}(\mathrm{CPa})$ \\
\hline Polypropylene & $20.5 \pm 0.8$ & $492 \pm 10$ & $375 \pm 9$ & $35.5 \pm 1.1$ & $1.9 \pm 0.2$ \\
Untreated OF/PP & $33.2 \pm 0.9$ & $615 \pm 8$ & $9.5 \pm 0.2$ & $57.2 \pm 1.3$ & $3.9 \pm 0.3$ \\
Treated OF/PP & $38.5 \pm 0.7$ & $675 \pm 8$ & $8.2 \pm 0.3$ & $72.5 \pm 1.2$ & $5.4 \pm 0.1$ \\
\hline
\end{tabular}

Table 2: Comparative impact strength and hardness of unreinforced PP sheet and the optimized composites (45\% fiber content) found in this study

\begin{tabular}{lll}
\hline Materials & Impact Strength $\left(\mathrm{KJ} / \mathrm{m}^{2}\right)$ & Hardness $($ Shore-A) \\
\hline Polypropylene & $4.55 \pm 0.2$ & $92 \pm 0.5$ \\
Untreated OF/PP & $20.84 \pm 0.2$ & $95 \pm 0.5$ \\
Treated OF/PP & $22.87 \pm 0.3$ & $97 \pm 0.5$ \\
\hline
\end{tabular}

\subsection{Influence of $\gamma$ Radiation on Mechanical Characteristics of the Composites}

The impression of $\gamma$ radiation on tensile, impact and bending properties of the composites was inspected by optimized composites ( $45 \%$ fiber). The obtained data reported that the mechanical properties increasing trend was found from 2.5-5.0 kGy dose and after that the values decrease up to $10.0 \mathrm{kGy}$ dose for both untreated and treated fiber composites. Best mechanical properties were obtained using $5.0 \mathrm{kGy}$ of total $\mathrm{p}$ dose at $3.3 \mathrm{kGy} / \mathrm{h}$. 
Maximum value of TS, TM, BS, BM and IS of raw fiber composites were examined to be $41.9 \mathrm{MPa}, 680 \mathrm{MPa}, 70$ $\mathrm{MPa}, 4.8 \mathrm{GPa}$ and $22.9 \mathrm{KJ} / \mathrm{m}^{2}$ respectively and for treated fiber composites the optimum TS, TM, BS, BM and IS values were 48.8 MPa, 755 MPa, 92 MPa, 7.2 $\mathrm{GPa}$ and $24.9 \mathrm{KJ} / \mathrm{m}^{2}$ respectively. For untreated fiber composite, about $26 \%$ improve in TS, $11 \%$ increment in TM, 28\% increase in BS, 23\% improvement in BM and $10 \%$ increment in IS was found compared to non-irradiated sample. For composite made of treated fiber, about $27 \%$ improvement in TS, $12 \%$ increment in TM, 27\% improvement in BS, 33\% higher in BM and $9 \%$ improvement in Is was found compared to non-irradiated composite.

The mechanical characteristics of the resultant composite are effected by the strength of interfacial bond between PP and reinforcing fiber. Interfacial bond strength was developed due to $\gamma$ treatment by generating active sites. Subsequently, due to the formation of cross-link, the mechanical attributes of the irradiated composites were enriched up to $5.0 \mathrm{kGy}$ dose. It may be supposed that stress transfer between fiber and matrix was better at 5.0 $k G y$ dose which leads to cracks avoiding at the fiber. A possible reaction mechanism between cellulose and polypropylene during irradiation treatment is given in Figure 9 (a) and (b). Figures indicate that $\gamma$ irradiation directly affects the internal configuration of the cellulosic fiber and creates some active sites in OF and PP by subtraction of electrons which lead to form OF/PP complex and as a result, better interfacial bonding could occur between them. This complex formation might be the motive behind the enhanced mechanical properties [42]. But above $5.0 \mathrm{kGy}$ dose, the irradiated composites showed reduced mechanical properties. The fact behind that, due to acquaintance of high energy $\gamma$ radiation the polymer chains are broken which causes the degradation of PP matrix and cellulose backbone. During the degradation, due to breakage of primary bond in the cellulose components, the strength will loose and therefore, the deviations take place in the central lamella, which reduce the ultimate strength [43].

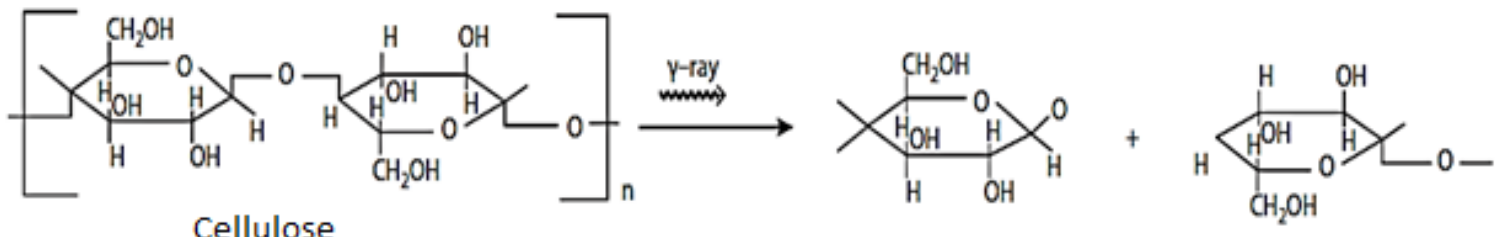

Figure 9: (a) Chain scission mechanism of cellulose during $y$ irradiation<smiles>CC(O)C(O)C([O-])O</smiles>

Cellulose<smiles>CCC(C)C[O+]CC(C)C(O)C(C)O</smiles>

Cellulose<smiles>CCCC(C)CC</smiles>

PP

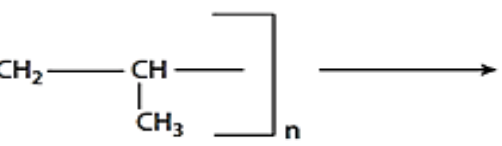

PP<smiles>CCC(C)OC1OC(C)CCC1O</smiles><smiles>CCC(C)C(C)C1C(C)OC(CO)C(O)C1C</smiles>

Cellulose/PP Complex

Figure 9: (b) A possible cross-linking mechanism between cellulose and PP molecules.

\subsection{Water Absorption Behavior of the Composites}

The optimized composite samples ( $45 \%$ fiber content) were dipped in deionized stationary water bath for around 90 hrs. The mass of the samples was determined by with drawling them after a certain time interval from the water bath. The obtained results were shown in Figure 10 against time. It was examined that the virgin composite samples showed a considerable amount of absorption than treated one. The absorption rate was optimum within the first $10 \mathrm{hr}$ by both type of samples, and then the swelling rate became slow and static with time for treated composite, while the virgin sample continued to soak water very slowly. The virgin composite specimen gained highest water absorption up to $9.85 \%$, whereas the treated sample yielded $7.12 \%$ water of its weight. The cause for lower absorption by the treated specimen might be the fact that vacant space of fiber filled by the polymer. 
Creation of intermolecular hydrogen bonds with neighboring cellulose can be the reason for increasing moisture absorption. Due to alkali treatment, some of the hydroxyl groups are replaced and the hygroscopicity of lingocellulosic fiber is reduced. Mercerization also increased crystallinity in the fiber. In the crystalline part, the hydroxyl groups are cross-linked so, there is no space available to retain water [43].

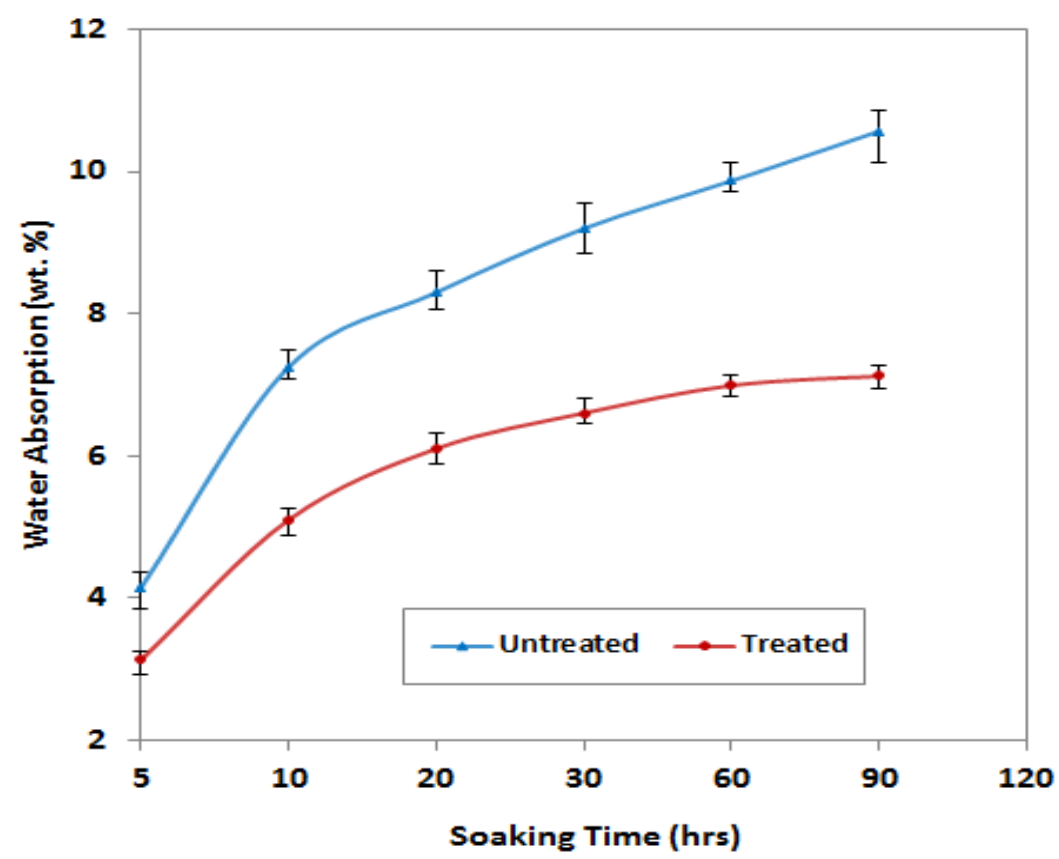

Figure 10: Water absorption of the optimized composites (45\% fiber) against different soaking period.

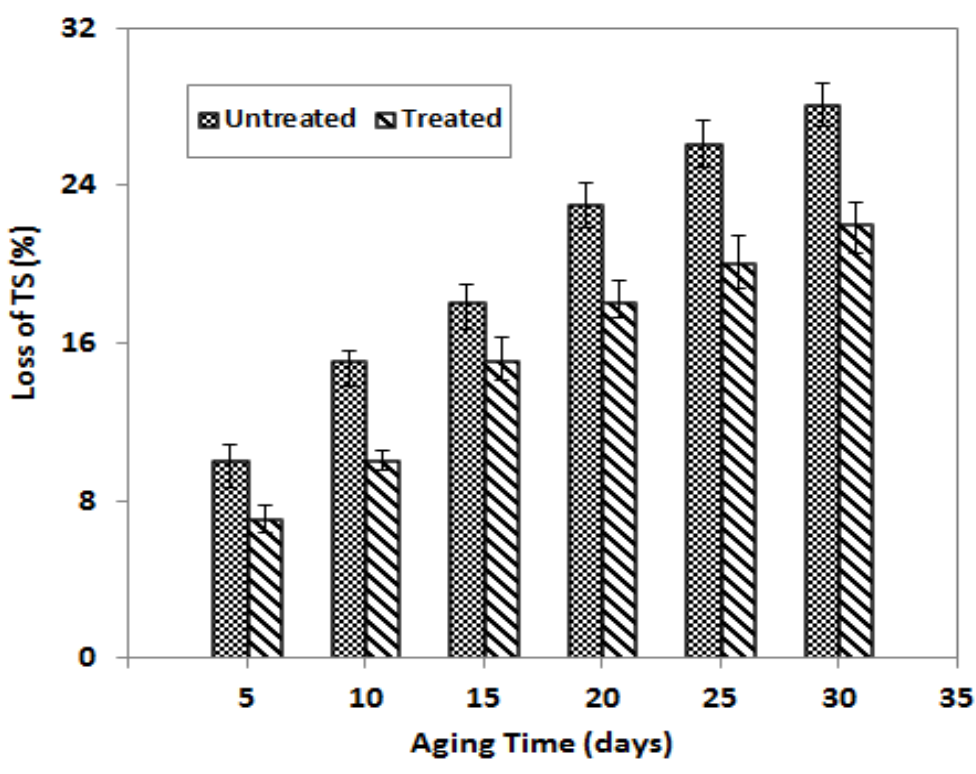

Figure 11: Loss of tensile strength of the optimized composites ( $45 \%$ fiber) against time.

\subsection{Thermal Degradation of the Composites}

Degradation of the composites in heat medium was done by heating the specimens in an oven for 30 days at $90^{\circ} \mathrm{C}$. The TS of the composite samples was determined after a certain period and loss (\%) of TS is shown in Figure 11. The raw and mercerized samples lost the tensile strength of $28,22 \%$ respectively after 30 days of thermal aging and the values were 23.8 and $29.9 \mathrm{MPa}$ respectively. From thermal degradation test, it is noticed that the 
untreated composite lost a considerable amount of tensile properties while the treated one retained much of their properties. The degradation behavior of fiber-reinforced composites is related to the breakage of glycosidic linkages of cellulose firstly; the second relevant to the depolymerization of the $\alpha$-cellulose, hemicellulose and pectin [44].

\subsection{Soil Degradation Study}

The discontinuous fiber composites of $45 \%$ fiber content were buried in soil and degradation test was carried out up to 24 weeks. The results of TS and TM were shown in Figure 12 and 13. It was clear for both types of composites that, the tensile properties lessened phenomenally with time interval. After 8 weeks observation, untreated and treated OF composites lost nearly 20 and 16\% of TS, 9 and 7\% of TM respectively. After 5 months of soil degradation, both untreated and treated fiber composites showed a substantial loss of strength. Virgin and mercerized fiber composites lost 32 and 26\% strength respectively. In the same period, untreated fiber composites lost almost 17\% TM and treated fiber composites lost 15\% TM. The value of tensile strength and modulus was found to be 22.5 and $510 \mathrm{MPa}$ for untreated and 28.8 and $572 \mathrm{MPa}$ for the treated sample after 5 months of degradation. The strong attraction was found in cellulosic fibers to damage when they are kept under the soil medium. The water molecule enters into the cutting ends of the composites under the soil medium and as a result, the cellulose degraded sufficiently which reduce the tensile properties of the composites significantly.

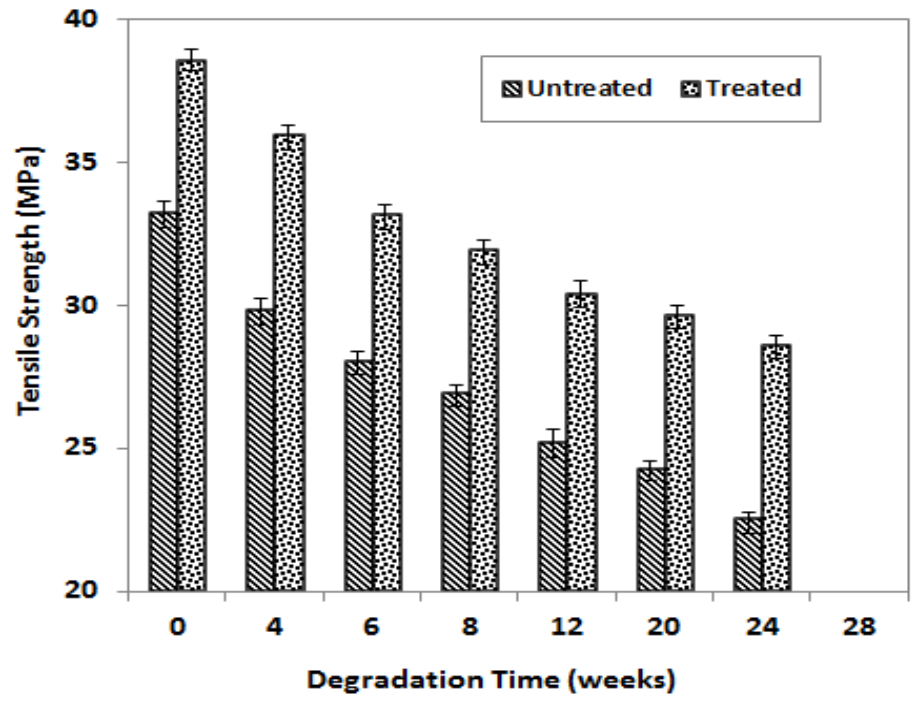

Figure 12: Tensile strength degradation of the optimized composites ( $45 \%$ fiber) in soil medium.

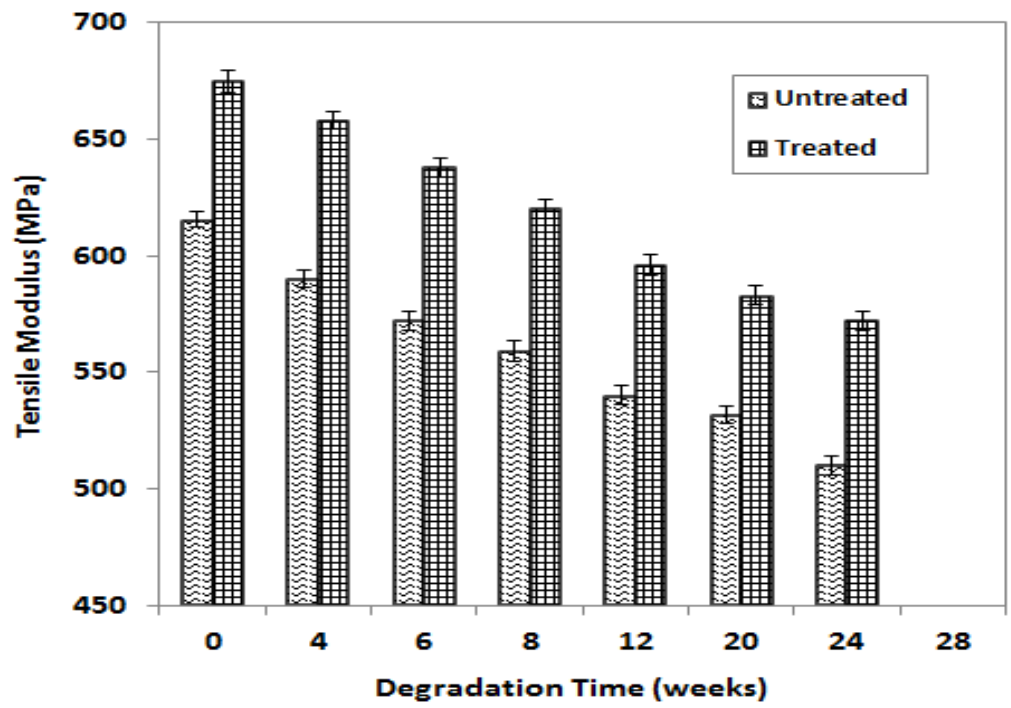

Figure 13: Tensile modulus degradation of the optimized composites ( $45 \%$ fiber) in soil medium. 


\subsection{Examination of Interfacial Properties}

SEM micrographs were used to understand the interfacial bonding of the composites. Figures 14 (a), (b) and Figures 14 (c) and (d) show the tensile fracture surface of the virgin and mercerized composites (45\% fiber). The figures specified that the raw fiber partly adhered to the binder material, demonstrating the weak interfacial bonding between fiber and matrix.

It is detected that the fiber diameters are different and found 0.08-0.20 mm (Figure 15), the fiber surface is harsh and small amount of fibers and particles adhered. On the other hand, the mercerized fiber was entirely bounded with the PP matrix demonstrating an improved fiber-matrix bonding. As a result enhanced stress transfer occurred between the reinforcing fibers and matrix material. From the images, the debonding of the PP and OF is also found. These recommend that the bonding between matrix and reinforcing fiber can be developed further. The physico-mechanical behaviors of composites significantly depend on the interfacial bond strength between reinforcement and matrix. Therefore, it is reflected that the tensile, bending and impact behaviors of the composite material can be further optimized by the use of appropriate coupling agents.

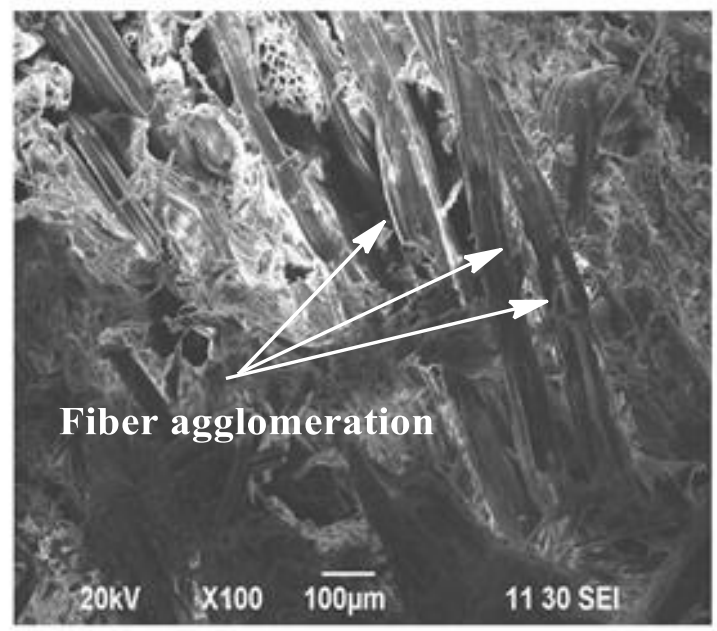

(a)

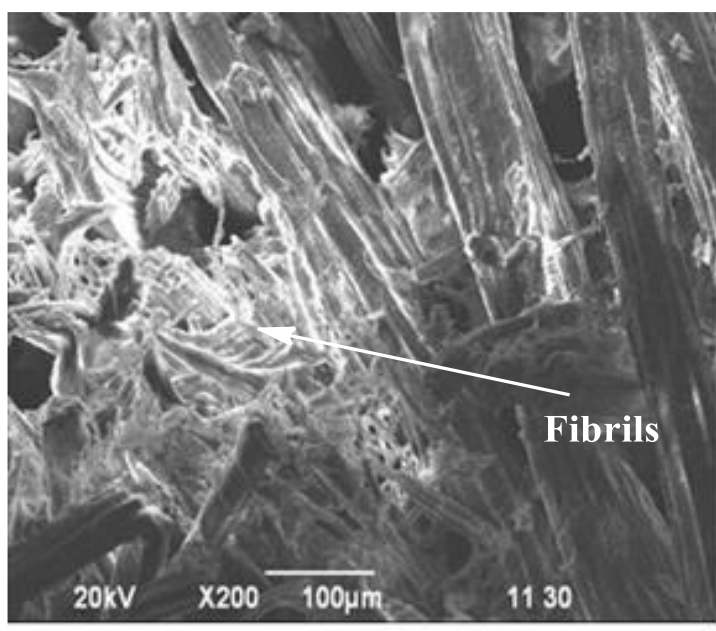

(b)

Figure 14: (a), (b) SEM micrographs of untreated fiber composite

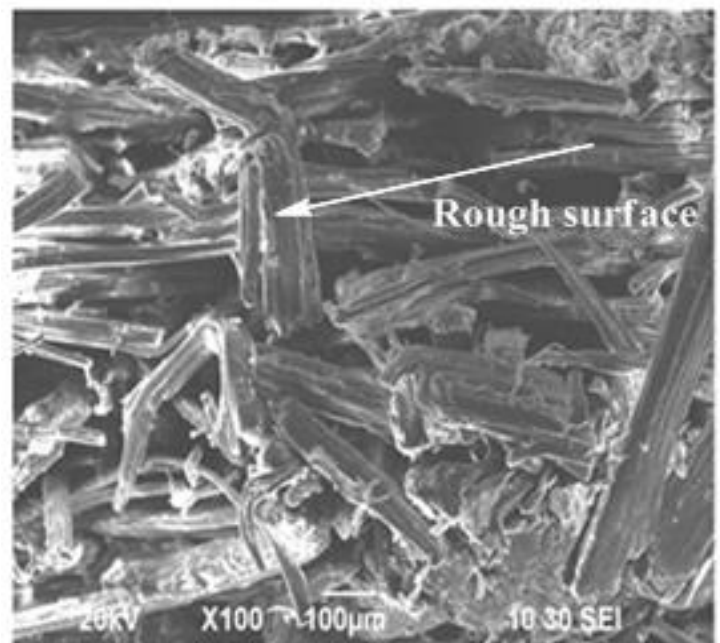

(c)

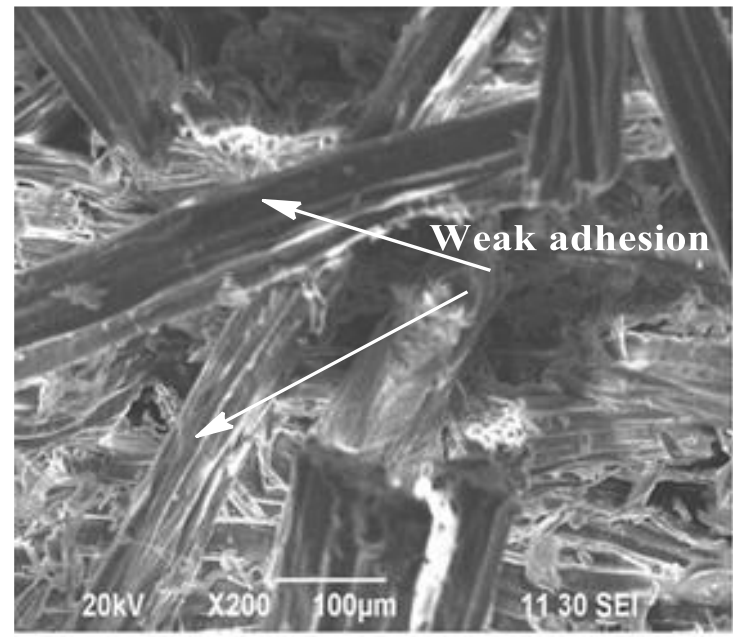

(d)

Figure 14: (c), (d) SEM micrographs of treated fiber composite 


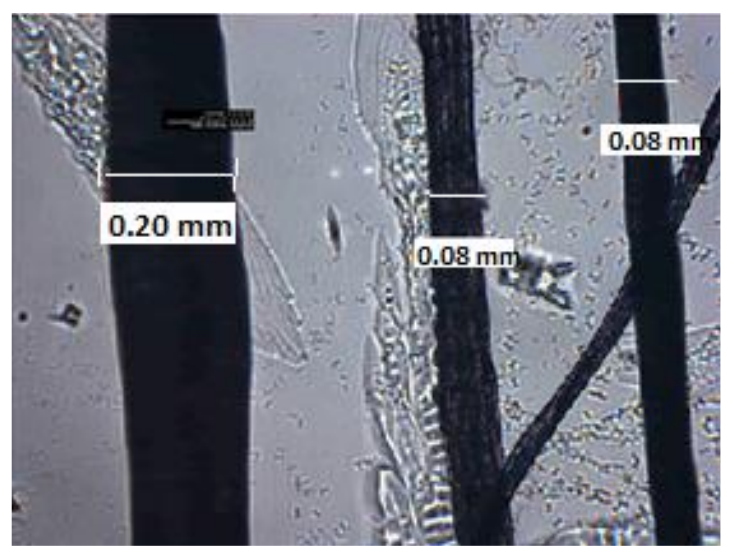

(a)

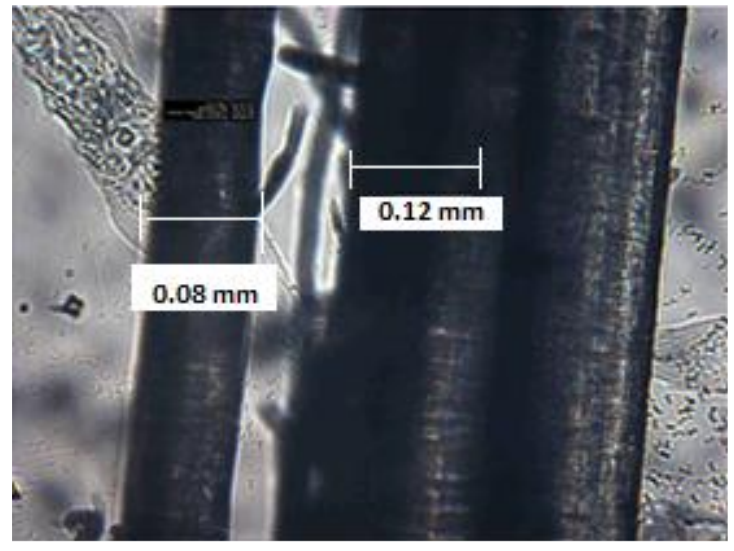

(b)

Figure 15: (a), (b) Microscopic view of fibers with the measurement of diameter

\section{CONCLUSIONS}

Okra fiber reinforced polypropylene composites were fabricated successfully using compression molding technique and physicomechanical behaviors were assessed. It can be concluded that:

1. The tensile, impact and bending behaviors of the resultant mercerized fiber composites were enriched than the virgin fiber composites. The investigation also showed that at $45 \%$ fiber content, the mechanical performance of the composites was the best than all other fiber content.

2. The soil and thermal resistance behaviors of composites were developed when composites were mercerized. Water absorption capability was also reduced due to mercerization. $\gamma$ irradiation was found to be a potential source to improve the physicomechanical properties of OF/PP composites. Soil degradation test indicated that the composites retained their inherent biodegradation behavior.

3. SEM analysis revealed that fiber and PP matrix was in good adhesion and also weak interfacial bonding was found due to agglomeration of randomly orientated fibers which reduces the ultimate mechanical properties of the composites. SEM image also indicated that the interfacial affection between polypropylene and fiber could be developed further by using coupling agent with the proper embedding of fibers during manufacturing of composites.

4. The tensile fracture samples were selected for SEM analysis only. If SEM could be done on bending and impact strength tested samples it would be more supportive to observe the interfacial bonding between reinforcement and matrix material.

5. Finally, it had been observed that OF/PP composites possessed sufficient physical and mechanical properties which established that okra fiber can be a potential candidate for using as reinforcement in the polymer composite area for diversified applications.

\section{ACKNOWLEDGEMENT}

The authors are grateful to Dr. Mubarak Ahmad Khan, the Director General of Bangladesh Atomic Energy Commission, for giving the opportunity to conduct experimental works in Polymer Composite Laboratory under Institute of Radiation and Polymer Technology, Dhaka, Bangladesh.

\section{REFERENCES}

1. Alam, M. S., \& Khan, G. A. (2007). Chemical analysis of okra bast fiber (Abelmoschus esculentus) and its physico-chemical properties. Journal of Textile and Apparel Technology and Management, 5(4).

2. Albano, C., Gonzalez, J., Ichazo, M., \& Kaiser, D. (1999). Thermal stability of blends of polyolefins and sisal fiber. Polymer Degradation and Stability, 66(2), 179-190.

3. Ayre, B. G., Stevens, K., Chapman, K. D., Webber, C. L., Dagnon, K. L., \& D'Souza, N. A. (2009). Viscoelastic properties of kenaf bast fiber in relation to stem age. Textile Research Journal, 79(11), 973-980.

4. Blouin, F. A., \& Arthur, J. C. (1958). The Effects of Gamma Radiation on Cotton Part I: Some of the Properties of Purified Cotton Irradiated in Oxygen and Nitrogen Atmospheres. Textile Research Journal, 28(3), 198-204.

5. Botelho, E., Pardini, L., \& Rezende, M. (2005). Hygrothermal effects on damping behavior of metal/glass fiber/epoxy hybrid composites. Materials Science and Engineering: A, 399(1), 190-198.

6. Bullions, T., Gillespie, R., Price-O'Brien, J., \& Loos, A. (2004). The effect of maleic anhydride modified polypropylene on the mechanical properties of feather fiber, kraft pulp, polypropylene composites. Journal of Applied Polymer Science, 92(6), 3771-3783. 
7. Cantero, G., Arbelaiz, A., Llano-Ponte, R., \& Mondragon, I. (2003). Effects of fibre treatment on wettability and mechanical behaviour of flax/polypropylene composites. Composites Science and Technology, 63(9), 1247-1254.

8. Cheung, H.-Y., Lau, K.-T., Tao, X.-M., \& Hui, D. (2008). A potential material for tissue engineering: Silkworm silk/PLA biocomposite. Composites Part B: Engineering, 39(6), 1026-1033.

9. Czvikovszky, T. (1995). Reactive recycling of multiphase polymer systems through electron beam. Nuclear Instruments and Methods in Physics Research Section B: Beam Interactions with Materials and Atoms, 105(1-4), 233-237.

10. Dey, K., Khan, R. A., \& Chowdhury, A. S. (2012). Study on the mechanical, degradation, and interfacial properties of calcium alginate fiber-reinforced polyethylene oxide composites. Journal of Thermoplastic Composite Materials, 25(7), 807-819.

11. Fortunati, E., Puglia, D., Monti, M., Santulli, C., Maniruzzaman, M., Foresti, M., Vazquez, A. \& Kenny, J.M. (2013). Okra (Abelmoschus esculentus) fibre based PLA composites: mechanical behaviour and biodegradation. Journal of Polymers and the Environment, 21(3), 726-737.

12. Fortunati, E., Puglia, D., Monti, M., Santulli, C., Maniruzzaman, M., \& Kenny, J. M. (2013). Cellulose nanocrystals extracted from okra fibers in PVA nanocomposites. Journal of Applied Polymer Science, 128(5), 3220-3230.

13. Gogus, F., \& Maskan, M. (1999). Water adsorption and drying characteristics of okra Hibiscus esculentus $L$. Drying Technology, 17(4-5), 883-894.

14. Gowda, T. M., Naidu, A., \& Chhaya, R. (1999). Some mechanical properties of untreated jute fabricreinforced polyester composites. Composites Part A: Applied Science and Manufacturing, 30(3), 277-284.

15. Hassan, M. M., Islam, M. R., \& Khan, M. A. (2005). Surface modification of cellulose by radiation pretreatments with organo-silicone monomer. Polymer-Plastics Technology and Engineering, 44(5), 833-846.

16. Idicula, M., \& Thomas, S. (2004). Effect of fibre loading and fibre ratio on the mechanical properties of intimately mixed banana/sisal hybrid fibre reinforced composites. Paper presented at the 5th Global Wood and Natural Fibre Composites Symposium, Kassel, Germany.

17. Islam, T., Khan, R. A., Khan, M. A., Rahman, M. A., Fernandez-Lahore, M., Huque, Q., \& Islam, R. (2009). Physico-mechanical and degradation properties of gamma-irradiated biocomposites of jute fabric-reinforced poly (caprolactone). Polymer-Plastics Technology and Engineering, 48(11), 1198-1205.

18. Jawaid, M., Khalil, H. A., Bakar, A. A., \& Khanam, P. N. (2011). Chemical resistance, void content and tensile properties of oil palm/jute fibre reinforced polymer hybrid composites. Materials \& Design, 32(2), 1014-1019.

19. John, K., \& Naidu, S. V. (2004). Sisal fiber/glass fiber hybrid composites: the impact and compressive properties. Journal of Reinforced Plastics and Composites, 23(12), 1253-1258.

20. Joseph, P., Joseph, K., \& Thomas, S. (2002). Short sisal fiber reinforced polypropylene composites: the role of interface modification on ultimate properties. Composite Interfaces, 9(2), 171-205.

21. Karina, M., Onggo, H., Abdullah, A. D., \& Syampurwadi, A. (2008). Effect of oil palm empty fruit bunch fiber on the physical and mechanical properties of fiber glass reinforced polyester resin. Journal of Biological Sciences, 8(1), 101-106.

22. Khalil, H. A., Hanida, S., Kang, C., \& Fuaad, N. N. (2007). Agro-hybrid composite: the effects on mechanical and physical properties of oil palm fiber (EFB)/glass hybrid reinforced polyester composites. Journal of Reinforced Plastics and Composites, 26(2), 203-218.

23. Khan, G. A., Shaheruzzaman, M., Rahman, M., Razzaque, S. A., Islam, M. S., \& Alam, M. S. (2009). Surface modification of okra bast fiber and its physico-chemical characteristics. Fibers and Polymers, 10(1), 65-70.

24. Khan, M., Hinrichsen, G., \& Drzal, L. (2001). Influence of novel coupling agents on mechanical properties of jute reinforced polypropylene composite. Journal of Materials Science Letters, 20(18), 1711-1713.

25. Khan, M., Kopp, C., \& Hinrichsen, G. (2001). Effect of vinyl and silicon monomers on mechanical and degradation properties of bio-degradable Jute-Biopol ${ }^{\circledR}$ composite. Journal of Reinforced Plastics and Composites, 20(16), 1414-1429.

26. Khan, M. A., Khan, R. A., Haydaruzzaman, Ghoshal, S., Siddiky, M., \& Saha, M. (2009). Study on the physicomechanical properties of starch-treated jute yarn-reinforced polypropylene composites: effect of gamma radiation. Polymer-Plastics Technology and Engineering, 48(5), 542-548.

27. Khan, R. A., Khan, M. A., Sarker, B., Saha, S., Das, A. K., Noor, N., . . Saha, M. (2010). Fabrication and Characterization of Gelatin Fiber-based Linear Low-density Polyethylene Foamed Composite. Journal of Reinforced Plastics and Composites, 29(16), 2438-2449.

28. Lapique, F., Meakin, P., Feder, J., \& Jøssang, T. (2000). Relationships between microstructure, fracture-surface morphology, and mechanical properties in ethylene and propylene polymers and copolymers. Journal of Applied Polymer Science, 77(11), 2370-2382.

29. Miah, M., Ahmed, F., Hossain, A., Khan, A., \& Khan, M. A. (2005). Study on mechanical and dielectric properties of jute fiber reinforced low-density polyethylene (LDPE) composites. Polymer-Plastics Technology and Engineering, 44(8-9), 1443-1456.

30. Mishra, A., \& Pal, S. (2007). Polyacrylonitrile-grafted Okra mucilage: A renewable reservoir to polymeric materials. Carbohydrate Polymers, 68(1), 95-100. 
31. Mishra, S., Mohanty, A. K., Drzal, L. T., Misra, M., \& Hinrichsen, G. (2004). A review on pineapple leaf fibers, sisal fibers and their biocomposites. Macromolecular Materials and Engineering, 289(11), 955-974.

32. Mohanty, A., Khan, M. A., \& Hinrichsen, G. (2000). Surface modification of jute and its influence on performance of biodegradable jute-fabric/Biopol composites. Composites Science and Technology, 60(7), 1115-1124.

33. Mohanty, A., Misra, M., \& Hinrichsen, G. (2000). Biofibres, biodegradable polymers and biocomposites: an overview. Macromolecular Materials and Engineering, 276(1), 1-24.

34. Monteiro, S. N., Calado, V., Rodriguez, R. J., \& Margem, F. M. (2012). Thermogravimetric stability of polymer composites reinforced with less common lignocellulosic fibers-an Overview. Journal of Materials Research and Technology, 1(2), 117-126.

35. Pan, P., Zhu, B., Dong, T., Serizawa, S., lji, M., \& Inoue, Y. (2008). Kenaf fiber/poly ( $\varepsilon$-caprolactone) biocomposite with enhanced crystallization rate and mechanical properties. Journal of Applied Polymer Science, 107(6), 3512-3519.

36. Rahman, M. R., Huque, M. M., Islam, M. N., \& Hasan, M. (2008). Improvement of physico-mechanical properties of jute fiber reinforced polypropylene composites by post-treatment. Composites Part A: Applied Science and Manufacturing, 39(11), 1739-1747.

37. Rajulu, A. V., \& Devi, R. R. (2007). Tensile properties of ridge gourd/phenolic composites and glass/ridge gourd/phenolic hybrid composites. Journal of Reinforced Plastics and Composites, 26(6), 629-638.

38. Saba, N., Paridah, M., \& Jawaid, M. (2015). Mechanical properties of kenaf fibre reinforced polymer composite: a review. Construction and Building Materials, 76, 87-96.

39. Sathishkumar, T., Navaneethakrishnan, P., Shankar, S., Rajasekar, R., \& Rajini, N. (2013). Characterization of natural fiber and composites-A review. Journal of Reinforced Plastics and Composites, 32(19), 1457-1476.

40. Sawpan, M. A., Khan, M. A., \& Abedin, M. (2003). Surface modification of jute yarn by photografting of lowglass transition temperature monomers. Journal of Applied Polymer Science, 87(6), 993-1000.

41. Shubhra, Q. T., Alam, A., \& Quaiyyum, M. (2013). Mechanical properties of polypropylene composites: A review. Journal of Thermoplastic Composite Materials, 26(3), 362-391.

42. Zaman, H. U., Khan, A., Hossain, M., Khan, M. A., \& Khan, R. A. (2009). Mechanical and electrical properties of jute fabrics reinforced polyethylene/polypropylene composites: role of gamma radiation. Polymer-Plastics Technology and Engineering, 48(7), 760-766.

43. Zaman, H. U., Khan, M. A., Khan, R. A., Mollah, M., Pervin, S., \& Al-Mamun, M. (2010). A comparative study between gamma and UV radiation of jute fabrics/polypropylene composites: effect of starch. Journal of Reinforced Plastics and Composites, 29(13), 1930-1939.

44. Zaman, H. U., Khan, R. A., Khan, M. A., \& Beg, M. D. H. (2013). Physico-mechanical and degradation properties of biodegradable photografted coir fiber with acrylic monomers. Polymer Bulletin, 70(8), 22772290. 